\title{
Nanoindentation of bone: Comparison of specimens tested in liquid and embedded in polymethylmethacrylate
}

\author{
A.J. Bushby \\ Department of Materials, Queen Mary, University of London, London E1 4NS, United Kingdom \\ V.L. Ferguson \\ Department of Materials, Queen Mary, University of London, London E1 4NS, and \\ Department of Anatomy and Developmental Biology, University College London, \\ London WC1E 6BT, United Kingdom \\ A. Boyde \\ Department of Anatomy and Developmental Biology, University College London, London WC1E 6BT, \\ and Dental Biophysics, Centre for Oral Growth and Development, Queen Mary, University of \\ London, Institute of Dentistry, London E1 2AD, United Kingdom
}

(Received 16 June 2003; accepted 8 October 2003)

Elastic modulus of bone was investigated by nanoindentation using common methods of sample preparation, data collection, and analysis, and compared to dynamic mechanical analysis (DMA: three-point bending) for the same samples.

Nanoindentation (Berkovich, $5 \mu \mathrm{m}$ and $21 \mu \mathrm{m}$ radii spherical indenters) and DMA were performed on eight wet and dehydrated (100\% ethanol), machined equine cortical bone beams. Samples were embedded in polymethylmethacrylate (PMMA) and mechanical tests repeated. Indentation direction was transverse to the bone long axis while DMA tested longitudinally, giving approximately $12 \%$ greater modulus in DMA. For wet samples, nanoindentation with spherical indenters revealed a low modulus surface layer. Estimates of the volume of material contributing to elastic modulus measurement showed that the surface layer influences the measured modulus at low loads. Consistent results were obtained for embedded tissue regardless of indenter geometry, provided appropriate methods and analysis were used. Modulus increased for nanoindentation $(21 \mu \mathrm{m}$ radius indenter) from $11.7 \mathrm{GPa} \pm 1.7$ to $15.0 \mathrm{GPa} \pm 2.2$ to $19.4 \mathrm{GPa} \pm 2.1$, for wet, dehydrated in ethanol, and embedded conditions, respectively. The large increases in elastic modulus caused by replacing water with ethanol and ethanol with PMMA demonstrate that the role of water in fine pore space and its interaction with collagen strongly influence the mechanical behavior of the tissue.

\section{INTRODUCTION}

Nanoindentation has proven to be a powerful technique for characterizing the mechanical properties of small volumes of material, such as thin films on dissimilar substrates. The technique has only recently been applied to the examination of biological materials and complements existing larger scale assays by allowing the study of individual micrometer- and submicrometersized structures. Nanoindentation provides a means to study many of the principal microstructural components in bone and other mineralized tissues, which often have dimensions of only a few micrometers and usually cannot be separated for independent study.

Bone is a heterogeneous material containing three main phases: mineral, collagen, and water, arranged in a series of hierarchical structures. Collagen contributes to bone's elastic and viscoelastic behavior while mineral stiffens the overall material. The degree of mineralization and collagen orientation highly influences mechanical properties. ${ }^{1,2}$ Mineralization is limited by the underlying construction, thus restricting the range of mechanical properties found in a single type of tissue. ${ }^{3}$ Bound and unbound water contribute to elasticity and ductility.

Preservation and processing may affect physical and mechanical properties of mineralized tissues. Machined sections of cortical bone stored in $70 \%$ alcohol for 1 week undergo a $25-45 \%$ increase in fracture toughness, and mechanical properties were restored after rehydration for 1 week in a physiological saline solution. ${ }^{4}$ Mechanical properties of whole bones or machined sections of cortical bones are maintained when stored frozen ${ }^{5}$ or when dehydrated and then rehydrated prior to mechanical testing. ${ }^{6}$ 
Smaller scale mechanical testing (e.g., nanoindentation) is more sensitive to preservation and processing techniques. It would be ideal to maintain and then simulate physiological conditions during a test. However, controlling environmental conditions, including humidity and temperature, interferes with the stability of most nanoindentation systems. More importantly, nanoindentation is a process that occurs on such a fine scale that its accuracy is affected by minute disturbances at the surface or near surface of the sample. This includes surface roughness, ${ }^{7}$ swelling, leaching of bone mineral or formation/ precipitation of mineral salts when the sample is immersed in solution, or even a thin film of water that, through capillary forces, may prematurely pull the indenter tip into the sample surface prior to the start of the test. The surface layer of mineralized tissues may profoundly be affected by mineral dissolution when stored in saline not buffered with calcium ${ }^{8}$ and may be dependent on the composition and $\mathrm{pH}$ of the storage media. ${ }^{9}$

Many of these factors may have a negligible effect in larger scale mechanical testing. For instance, dehydration and subsequent rehydration does not significantly affect the mechanical properties of whole bones ${ }^{5}$ or machined samples of cortical bone tissue, ${ }^{6}$ but subtle changes may be evident when using a more sensitive, smaller scale method of analysis. As an example, atomic force microscopy of demineralized, desiccated dentin showed complete morphological recovery but with permanent decreases in elastic modulus after rehydration. ${ }^{10,11}$ Published findings regarding the effects of tissue storage or processing methods on mechanical properties may not thus hold true at the nanoscale as little is known about the interaction between water and the organic or mineral phases in bone and how alterations in water content may influence near-surface mechanical properties.

Preparation of bone samples for microhardness testing typically involves inclusion of wet or dry bone in a noninfiltrating metallurgical resin and polishing to a generally flat surface. ${ }^{12,13}$ Nanoindentation requires a superior surface finish and has been performed on wet, dry, included, and embedded mineralized tissues. ${ }^{3,14-17}$ It is difficult to obtain an adequate surface finish on wet bone while maintaining hydration and preventing interaction with the hydrating fluid and collecting high-quality nanoindentation data. Full dehydration of bone tissue results in marked shrinkage, increased stiffness and strength, and reduced toughness. ${ }^{5,18}$ Bone embedded in polymethylmethacrylate (PMMA) permits highresolution analysis in scanning electron microscopy and nanoindentation. We have recently combined these techniques to match site-specific measurements of mineral composition and mechanical properties in PMMAembedded, micromilled human femoral heads. ${ }^{3}$ Polishing bone samples, embedded in PMMA, results in collagen orientation-related relief and scratches that extend to $1.5 \mu \mathrm{m}$ in depth. ${ }^{19}$ Surface roughness is reduced by micromilling, where typical peak-trough relief is $80 \mathrm{~nm}$. A typical nanoindentation may penetrate only about $1-2 \mu \mathrm{m}$ deep and thus may significantly be influenced by surface roughness due to polishing.

It remains unclear as to exactly what part of the bone construct is being tested at such a small scale. Bone collagen fibrils have a range of diameters, say from 50 to $300 \mathrm{~nm}$, and are arranged as parallel bundles typically 2 to $3 \mu \mathrm{m}$ in diameter. Berkovich indentation contact diameters are typically similar in size to bone lamellae and so could potentially be used to distinguish microstructural features. ${ }^{20,21}$ These same concerns apply regarding structural levels tested when performing nanoindentation at an even smaller scale with an atomic force microscope, which may penetrate to depths that are less than $150 \mathrm{~nm} .{ }^{16,22}$ This paper focuses on nanoindentation of bone from a microstructural perspective and examines the role of water and a continuum provided by infiltration of PMMA into equine third metacarpal (McIII) cortical bone.

\section{MATERIALS AND METHODS}

\section{A. Bone samples}

Cortical bone specimens were machined from third metacarpal bone from two 2-year-old thoroughbred horses. Eleven rectangular bone beams $(5.0 \times 2.0 \times$ $25 \mathrm{~mm}$ ), stored frozen prior to machining, were excised transversely from mid-shaft cortical bone from each animal. The large faces of each beam were cryo-polished over a liquid nitrogen precooled aluminum block using 600,800 , and 1200 grit silicon carbide papers and stored in $70 \%$ ethanol until subsequent mechanical testing.

Bone beams were hydrated in a buffered synthetic cartilage lymph (SCL) $(103 \mathrm{mM} \mathrm{NaCl}, 10.3 \mathrm{mM} \mathrm{KCl}$, $0.47 \mathrm{mM} \mathrm{KH}_{2} \mathrm{PO}_{4}, 0.95 \mathrm{mM} \mathrm{K}_{2} \mathrm{HPO}_{4}, 2.0 \mathrm{mM} \mathrm{CaCO}_{3}$, $0.57 \mathrm{mM} \mathrm{MgSO}, 1.8 \mathrm{mM} \mathrm{NaHCO}{ }_{3}, 16.5 \mathrm{mM}$ TES buffer, $5.6 \mathrm{mM}$ glucose, $64 \mathrm{mM}$ sucrose) for 2-3 h prior to mechanical testing. Each "wet" beam $(n=11)$ was subjected to nanoindentation testing and dynamic mechanical analysis (DMA) as described below and was kept in SCL for no more than $48 \mathrm{~h}$ to prevent degradation ex vivo.

Beams were then dehydrated in an ethanol series to enable the collection of large sets of nanoindentation data without any influence by changing environmental conditions (i.e., humidity) and to prevent shrinkage and cracking in air. Each "dehydrated" beam $(n=9)$ was again subjected to nanoindentation testing and DMA.

Eight of the bone beams were subsequently embedded in polymethylmethacrylate PMMA: ethanol was replaced with acetone, acetone with MMA monomer, and polymerized at $30{ }^{\circ} \mathrm{C}$. Embedded beams were carefully 
machined in an attempt to maintain the original dimensions and to remove all excess PMMA at each surface. The large faces of each beam were polished to a $1 \mu \mathrm{m}$ finish to facilitate nanoindentation testing and microscopy. The resulting beams measured $5.0 \times 1.1 \times 25 \mathrm{~mm}$. Again, each beam was tested using nanoindentation and DMA. Two of the embedded beams were excluded from the DMA testing as their cross-sectional areas were slightly trapezoidal in shape and thus unsuitable.

\section{B. Nanoindentation}

\section{Indentation arrays}

Nanoindentation testing was performed using a UMIS 2000 (CSIRO, Lindfield, NSW, Australia) using two different indenter tip geometries: spherical and Berkovich. Bone beams tested in wet and ethanol dehydrated conditions were glued, using a brittle cyanoacrylate adhesive, to the bottom of an optically flat polycarbonate Petri dish that was glued to a stainless steel mount. An optical microscope, affixed and aligned with the nanoindenter tip, was used to locate regions of evenly polished bone that lay adjacent to osteonal blood vessel canals aligned in the longitudinal axis of the McIII. Fluid in the wet and dehydrated conditions was added to the Petri dishes such that it covered the sample and extended at least $4 \mathrm{~mm}$ along the indenter shaft. This technique eliminates capillary forces upon initial contact by the indenter tip on liquid at the sample surface and minimizes the influence of meniscus forces on the indenter shaft. By keeping the meniscus on the straight part of the indenter shaft, the shape of the meniscus and its resultant forces do not change during indentation. To submerge the beams during each approximately $8-12 \mathrm{~h}$ test period, a cover was used to minimize evaporation (Fig. 1).

Indentation arrays $(10 \times n$, where $n=16$ to 32$)$ using a Berkovich, a small radius $(R=5 \mu \mathrm{m})$ and large radius

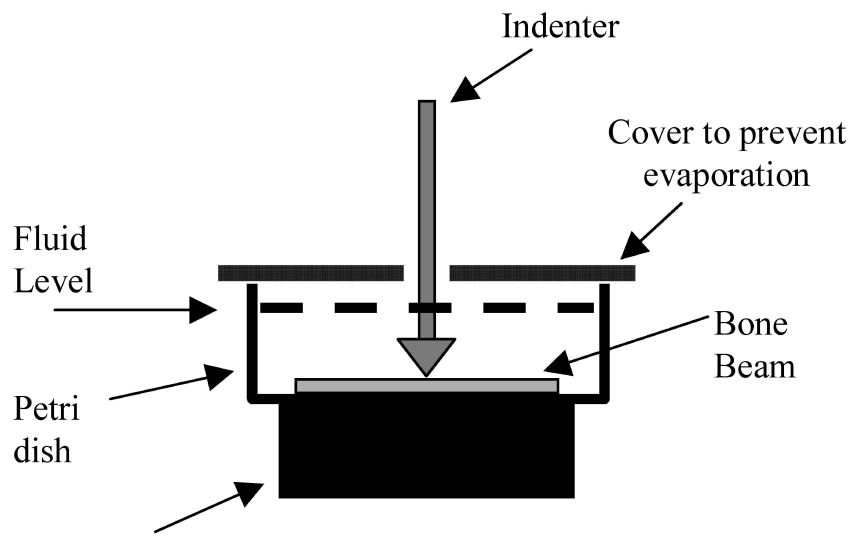

\section{Stainless Steel Mount}

FIG. 1. Schematic diagram of the arrangement to allow submersion of bone sample in wet calcium buffered solution or in $100 \%$ ethanol.
$(R=21 \mu \mathrm{m})$ spherical diamond indenter tip were located in the well polished regions, approximately $50 \mu \mathrm{m}$ from the nearest edges of the osteonal canals (tests lasted 6-12 h). Each array was designed such that it started with a column of ten indents made using the $R=21 \mu \mathrm{m}$ tip, followed by a column of Berkovich indents, and then by a column made using the $R=5 \mu \mathrm{m}$ tip. This pattern was repeated for the length of the array where spacing between indents was $50 \mu \mathrm{m}$ in the $x$ - and $y$-directions (Fig. 2). Deep, high load marker indents $(50 \mathrm{mN}, 50 \mathrm{mN}$, and $500 \mathrm{mN}$ for the Berkovich, $R=5 \mu \mathrm{m}$, and $R=$ $21 \mu \mathrm{m}$ tips, respectively) were placed at the starting end of each array for subsequent specimen orientation and identification of prior indent sites (not shown in Fig. 2). Arrays in wet and dehydrated conditions were located adjacent to, but not overlapping, each other.

Indentation testing was performed on only one face on each beam, and arrays were located away from areas in which the DMA fixture and crosshead may have contacted the sample. This ensured that nanoindentation testing was performed in surface regions that did not come into contact with the glue or regions that may have been affected by the larger scale mechanical testing.

\section{Berkovich indenter}

For Berkovich indentations, the tip was loaded into the surface of the bone to a maximum load of $5 \mathrm{mN}$. Preliminary work indicated that a $120 \mathrm{~s}$ maximum load hold was necessary to prevent creeping during unloading (Sec. III). After holding the maximum load for $120 \mathrm{~s}$, the indenter was unloaded to $10 \%$ of the maximum load, when $30 \mathrm{~s}$ of data was obtained during a second hold period. This second hold period is normally used for assessment of thermal stability, but for materials that display viscoelastic recovery the data can be misleading and so was not used. The tip shape and frame compliance of the Berkovich indenter tip were calibrated using a two-material reference material method using fused silica and single-crystal tungsten. ${ }^{23}$ Elastic modulus was

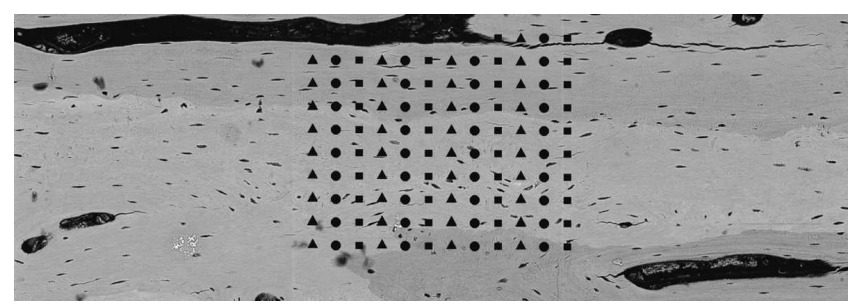

FIG. 2. Backscattered electron image of an embedded beam surface with an overlay depicting the relative position of the indentation array between osteonal canals. Squares represent indents made using the $R=5 \mu \mathrm{m}$ indenter tip, circles represent indents made using the $R=$ $21 \mu \mathrm{m}$ indenter tip, and triangles represent indents made using the Berkovich indenter tip. Indents were spaced at $50 \mu \mathrm{m}$ in $x$ - and $y$ directions. In general, the indentation arrays extended for 1-2 $\mathrm{mm}$ in the longitudinal axis of the bone. 
calculated using a method similar to that of Oliver and Pharr ${ }^{24}$ by fitting the first $45 \%$ of the unloading curve with a second-order polynomial, differentiating and evaluating the elastic recovery rate at maximum load to determine the contact depth (Sec. III. A. 1). The reduced modulus $\left(E_{\mathrm{r}}\right)$ is calculated from the unloading contact stiffness, $S$, and the indenter contact area, $A_{\mathrm{c}}$

$$
E_{r}=\frac{\sqrt{\pi}}{2} \frac{S}{\sqrt{A_{c}}},
$$

where $S=\mathrm{d} P / \mathrm{d} h$, with $P=$ load and $h=$ penetration depth. The reduced modulus is the result of the combined elastic displacement of the test surface and indenter, so that

$$
\frac{1}{E_{r}}=\frac{1}{E_{s}^{\prime}}+\frac{1}{E_{i}^{\prime}},
$$

where the subscripts $s$ and $i$ refer to the sample and the indenter materials, respectively, and $E^{\prime}$ is the plane strain modulus

$$
E_{x}^{\prime}=\frac{E_{x}}{1-v_{x}^{2}}
$$

where $E$ is the Young's modulus and $v$ is Poisson's ratio for material $x$. Equations (2) and (3) apply to the isotropic case. For anisotropic materials, the measured modulus is an appropriate combination of the stiffness tensor matrix.

Here we have reported the plane strain elastic modulus from Eq. (3), as determined from the experimental data, with the elastic contribution of the indenter accounted for via Eq. (2). This procedure eliminates any error of including an estimated value of Poisson's ratio but does not attempt to account for the anisotropy of the tissue.

\section{Spherical indenter}

Spherical indentations were performed using a multiple partial unloading technique. ${ }^{25,26}$ The area functions for the spherical indenter tips were calibrated by indentation into multiple reference materials. ${ }^{27}$ In brief, each indentation test consisted of 40 load increments, unloading to $75 \%$ of each load between increments to a maximum load of $15 \mathrm{mN}$ for the $R=5 \mu \mathrm{m}$ spherical indenter tip and $100 \mathrm{mN}$ for the $R=21 \mu \mathrm{m}$ spherical indenter tip. Elastic modulus was calculated as a function of contact depth $^{25,26}$ for each load-partial unload data pair, and a mean value of $E$ was derived for each indentation site from the 25 deepest indents (Fig. 6). Here, we report $E^{\prime}$ for spherical indentations to allow for better comparison with Berkovich indenter data. The reduced modulus, $E_{\mathrm{r}}$, is calculated using Hertzian contact mechanics from the elastic penetration depth $\left(h_{\mathrm{e}}\right)$ of the sphere under force $P$, given by

$$
E_{r}=\frac{3}{4} \frac{P}{h_{e}^{3 / 2}}\left(\frac{1}{R}-\frac{1}{R^{\prime}}\right)^{1 / 2},
$$

where

$$
\left(\frac{1}{R}-\frac{1}{R^{\prime}}\right)
$$

is the relative curvature between the sphere and residual impression in the surface. ${ }^{26} E^{\prime}$ is derived from $E_{\mathrm{r}}$, again, using Eqs. (2) and (3).

\section{Dynamic mechanical analysis}

Dynamic mechanical analysis (DMA; DMA-7, Perkin Elmer, Boston, MA) was performed to measure gross mechanical properties in each condition-wet, dry, and embedded - and to provide a gross verification of the nanoindentation results. After first performing nanoindentation testing, beams were carefully removed from the Petri dish. Residual adhesive was gently scraped off of the beam with the edge of a glass microscope slide, and the beam was then washed in SCL (wet conditions) or $100 \%$ ethanol (dry and embedded conditions). It is possible that a small amount of glue may have remained in the pore spaces, its overall contribution to the measured mechanical properties in DMA was assumed to be negligible.

DMA, in three-point bending mode $(20 \mathrm{~mm}$ span width; $800 \mathrm{mN}$ dynamic load, $1600 \mathrm{mN}$ static load), was performed on the same beams in the same conditions (wet, dehydrated, and embedded in PMMA) using a frequency sweep from 10 to $0.01 \mathrm{~Hz}$ after nanoindentation testing in each condition. Data reported for storage modulus are mean values over the range of frequencies tested, and take into account cross-sectional geometry of each specimen. ${ }^{28}$ For beams tested in wet and dehydrated (in 100\% ethanol) conditions, the beams were submerged in SCL or $100 \%$ ethanol during each about $2 \mathrm{~h}$ test period.

\section{RESULTS AND DISCUSSION}

\section{A. Nanoindentation technique}

\section{Berkovich indenter}

Conventional nanoindentation testing is based on elastic contact mechanics and adapted for elastic-plastic contact. This approach has successfully been applied to a wide range of metallic and ceramic materials in bulk and thin film form. However, this approach does not account for time-dependent behavior, including creep of ductile metals. Wet bone tissue (examples in Figs. 3 and 4) and many polymer systems are viscoelastic solids. Strategies for these materials have recently been explored to account for the viscoelastic behavior by indenting at 
different loading rates. ${ }^{29}$ The most commonly used approach for data from an indentation test at a single load rate is to allow the material to creep (i.e., increase in displacement, $h$ ) while holding the maximum load constant. Examples of the load versus penetration curves with no maximum load hold period, $120 \mathrm{~s}$ maximum load hold period, and $240 \mathrm{~s}$ maximum load hold period are shown in Fig. 3. With no hold at maximum load, the unloading curve is seen to bow out as the material continues to creep during the first part of unloading. ${ }^{30,31}$ Where the maximum load has been held, the additional penetration is obvious and is in this case similar for the $120 \mathrm{~s}$ and $240 \mathrm{~s}$ hold periods, indicating that the creep displacement has saturated. For viscoelastic materials, the effect of continued creep deformation during unloading is to increase the elastic recovery rate $(\mathrm{d} P / \mathrm{d} h)$ and increasing the apparent depth of contact $h_{\mathrm{c}}$, and hence contact area $A_{\mathrm{c}}$, the result of which is in an overestimate of the calculated value of elastic modulus [Eq. (1)], (Table I comparing "no max load hold" to " $120 \mathrm{~s}$ max load hold"). An example of additional displacement during the constant maximum load hold is shown in Fig. 4 and shows the typical logarithmic behavior associated with creep. At the start of the hold period, the creep rate is approximately $10 \mathrm{~nm} / \mathrm{s}$ reducing to $0.13 \mathrm{~nm} / \mathrm{s}$ after $120 \mathrm{~s}$. The unloading rate is approximately $5 \mathrm{~nm} / \mathrm{s}$. International Organization for Standardization (ISO) 14577 recommends the unloading rate should be at least $10 \times$ the creep rate at the end of the hold period, and this is clearly achieved for the $120 \mathrm{~s}$ hold period. Without the hold period, the creep rate at the start of unloading is twice the unloading rate, leading to the bowing out of the unload curve.

The unloading data is usually fitted with a function

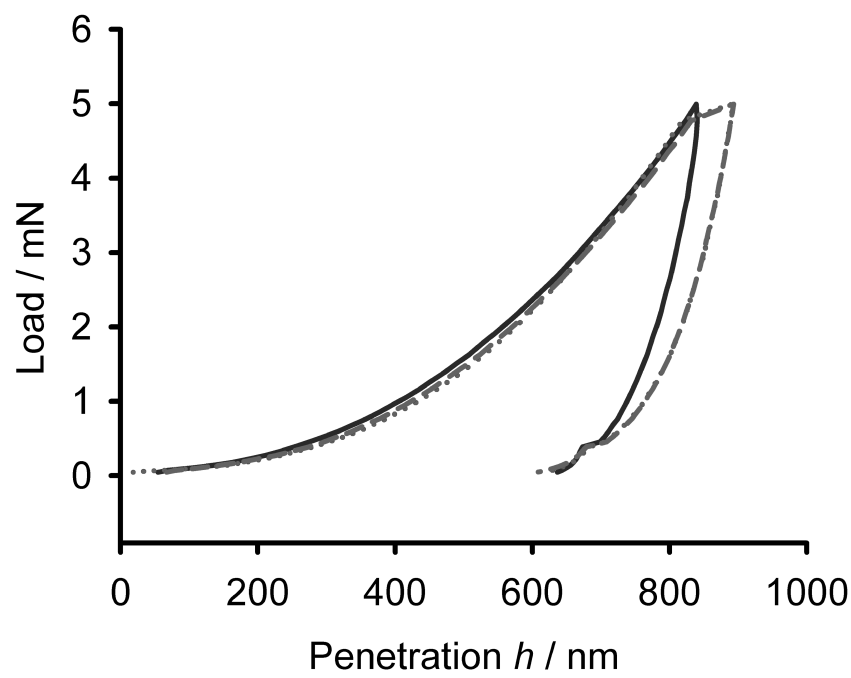

FIG. 3. Load/penetration curves for no hold (solid line), $120 \mathrm{~s}$ hold (dashed line), and $240 \mathrm{~s}$ hold (dotted line) at maximum load; where no hold at the maximum load significantly increased the calculated modulus value. and differentiated at the maximum load to determine the initial elastic recovery rate, $\mathrm{d} P / \mathrm{d} h$. This is commonly achieved by fitting the top $80 \%$ of the unloading curve with a power series function. ${ }^{24}$ However, viscoelastic recovery means the shape of the unloading curve is continually changing as the load reduces further toward zero. No single function is likely to fit the shape well. In Fig. 5, we examine the effect of fitting a quadratic equation to a varying proportion of the unload curve for an indentation with no maximum load hold and one with a $120 \mathrm{~s}$ maximum load hold. Table I gives the calculated values of elastic modulus, elastic recovery rate and calculated value of contact depth, $h_{\mathrm{c}}$, together with the degree of correlation $\left(r^{2}\right)$ for the fit. From Fig. 5(a), it is clear that a function may fit the unload curve very well in places and give a high value of $r^{2}$, but not represent the curve well during initial unloading. Fitting the upper $45 \%$ of the unload curve, following a suitable hold period to reduce the creep rate, results in a good fit to the initial unloading curve [Fig. 5(b)]. An inadequate hold period results in misleading values for elastic modulus. Fitting the upper part of the unload curve results in a reproducible value for both elastic modulus, $E$, and contact depth, $h_{\mathrm{c}}$ (Table I). The $r^{2}$ term is therefore not necessarily an indicator of a suitable fit to the curve.

\section{Spherical indenter}

The partial unloading technique ${ }^{25,26}$ used here for the spherical indenters allows the elastic modulus to be evaluated as a function of depth of penetration in a single indentation test, Fig. 6. The load rate in the partial unloading step is rapid $(\sim 10 \mathrm{mN} / \mathrm{s})$ and so reduces the effect of creep. The less severe stress field associated with spherical indenters also results in a reduced creep rate in the material. The elastic modulus versus depth of contact curve provides additional information on the condition of the sample. A constant value of modulus with depth is expected for isotropic elastic solids. However, surface roughness or softening of the surface results in a reduction in modulus close to the surface. The result is an increasing modulus at low penetration depths reaching a near constant value at greater depths. The situation can be modeled as a thin film problem, with a lower modulus layer on a stiffer substrate (the bulk material). It is relatively simple to simulate this situation in a finite element model and to generate the elastic response as a function of $a / t$, where $a$ is the radius of the circle of contact between indenter and surface and $t$ is the layer thickness, Fig. 7. Assuming the surface layer to have a modulus $50 \%$ of that of the substrate, then the elastic response becomes dominated by the substrate $(>90 \%$ of substrate modulus) at about $a / t \geqslant 1.5$. By averaging data points collected at deeper penetration, an approximation to the "substrate" value can be made. Furthermore, the standard deviation of that data gives an indication of the slope in 
TABLE I. Elastic modulus ( $\left.\mathrm{E}^{\prime}: \mathrm{GPa}\right)$, elastic recovery rate $(\mathrm{d} P / \mathrm{d} h)$, and contact depth $\left(h_{\mathrm{c}}: \mathrm{nm}\right)$ are presented for 0 and $120 \mathrm{~s}$ maximum load hold while loading a Berkovich tip into equine cortical bone dehydrated in $100 \%$ ethanol.

\begin{tabular}{|c|c|c|c|c|c|c|c|c|}
\hline \multirow{2}{*}{$\begin{array}{c}\text { Percentage of } \\
\text { unloading curve fitted }\end{array}$} & \multicolumn{4}{|c|}{ No max load hold } & \multicolumn{4}{|c|}{120 seconds max load hold } \\
\hline & $\mathrm{E}^{\prime}$ & $\mathrm{d} P / \mathrm{d} h$ & $h_{\mathrm{c}}$ & $r^{2}$ & $E^{\prime}$ & $\mathrm{d} P / \mathrm{d} h$ & $h_{\mathrm{c}}$ & $r^{2}$ \\
\hline 80 & 37.76 & 0.1913 & 819.38 & 0.999187 & 24.41 & 0.1298 & 863.98 & 0.997819 \\
\hline 60 & 29.24 & 0.1472 & 813.51 & 0.997965 & 13.67 & 0.0708 & 839.95 & 0.999778 \\
\hline 50 & 35.33 & 0.1788 & 818.00 & 0.996657 & 13.22 & 0.0684 & 838.03 & 0.999664 \\
\hline 45 & 41.06 & 0.2084 & 820.98 & 0.994541 & 12.53 & 0.0646 & 834.83 & 0.999786 \\
\hline 40 & 52.45 & 0.2674 & 824.95 & 0.993942 & 12.45 & 0.0642 & 834.43 & 0.999723 \\
\hline 33 & 128.50 & 0.6611 & 833.29 & 0.991043 & 12.67 & 0.0653 & 835.48 & 0.999504 \\
\hline \multirow[t]{2}{*}{30} & 3492.39 & 18.075 & 838.75 & 0.988646 & 12.60 & 0.0650 & 835.17 & 0.999273 \\
\hline & \multicolumn{4}{|c|}{$h_{\max }=838.96$} & \multicolumn{4}{|c|}{$h_{\max }=892.85$} \\
\hline
\end{tabular}

The degree of correlation $\left(r^{2}\right)$ is presented for second-order polynomial regression curves that were fit to $30-80 \%$ of each unloading curve.

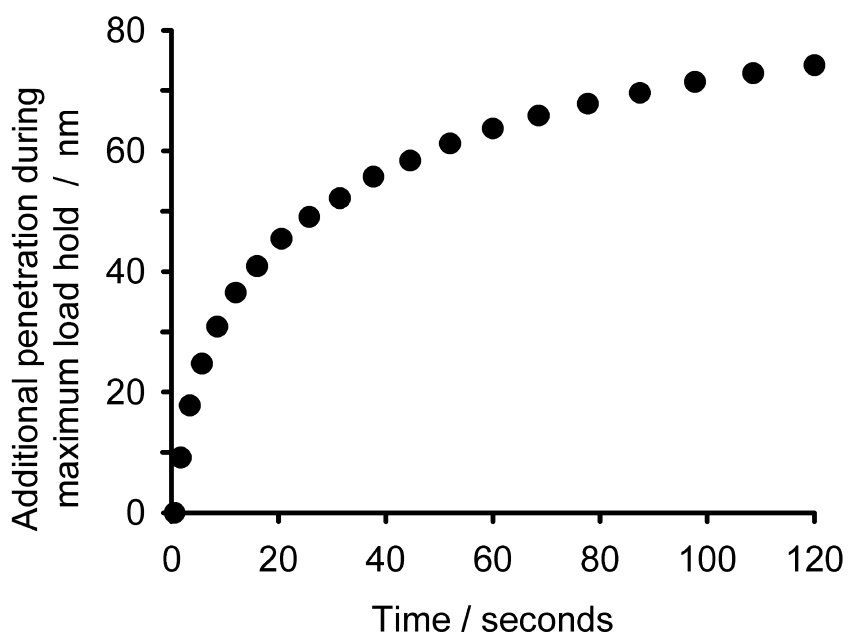

FIG. 4. Example of deflection data during maximum load $(5 \mathrm{mN})$ hold for $120 \mathrm{~s}$ using the Berkovich tip in wet conditions.

the data (i.e., the extent of surface softening). This model treats the near-surface region as a discrete layer whereas in reality it is likely to be graded and, if demineralized, may also be more viscoelastic than the bulk.

Several phenomena might contribute to the apparent stiffness of a near-surface layer. Surface roughness and contact asperities could result in the reduced surface stiffness observed in Fig. 6(a). The surface roughness of the wet and dehydrated samples was greater than that of the embedded samples due to the difficulties associated with polishing frozen samples. For bone samples in liquid environments, it has been observed that mineral may be lost from the near-surface region. For testing of whole bone samples, this has been shown to have little effect on measured properties. Nanoindentation, however, is a surface-sensitive technique and demineralization of the immediate surface layer would result in a reduced elastic modulus and a more viscoelastic response from this region, as has been noted for dentine. ${ }^{9}$ Furthermore, liquid may be trapped in the interior of the sample whereas the high stresses around the indentation may allow liquid to be squeezed out of the surface at the free surface, again
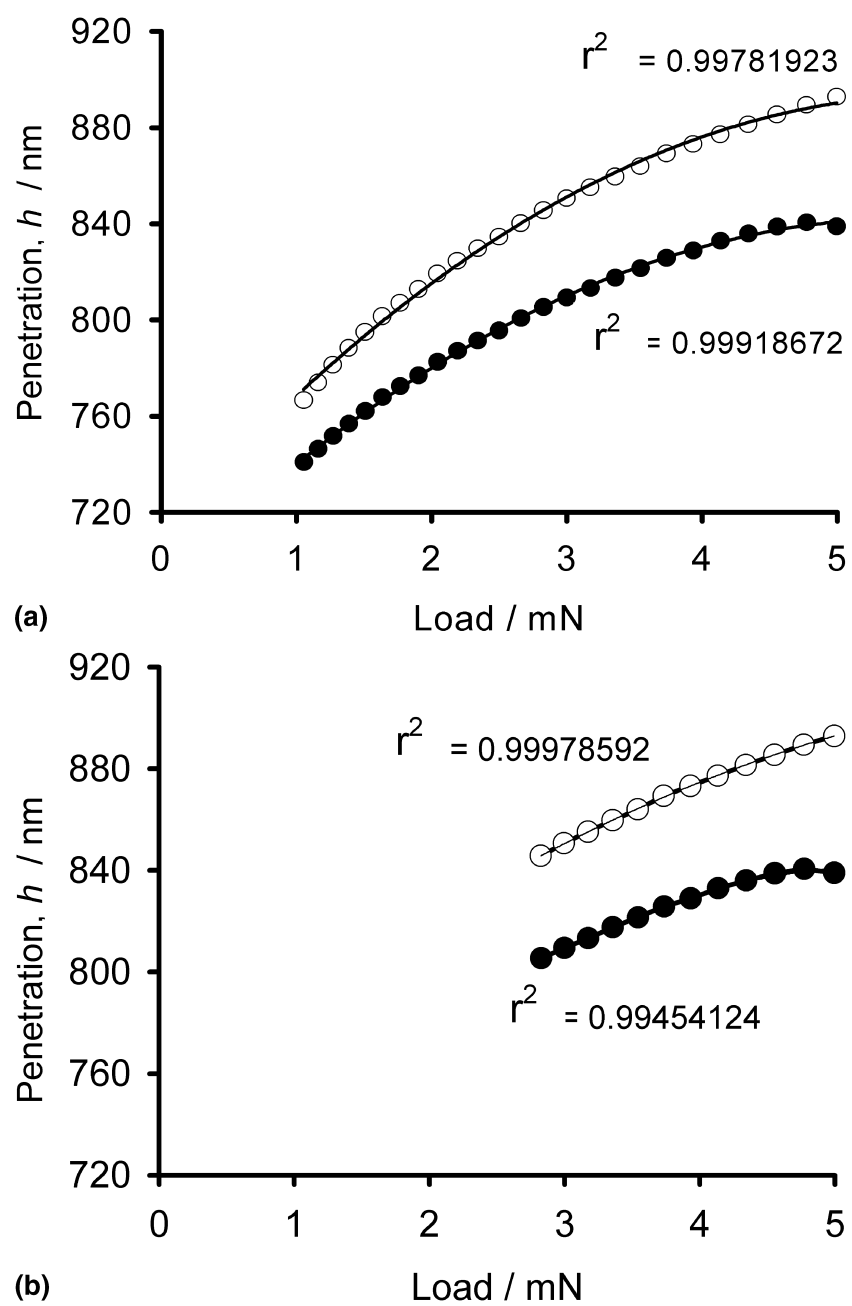

FIG. 5. Two plots each showing unloading curves and regression fits (using a second-order polynomial) at $0 \mathrm{~s}$ (solid circles) and $120 \mathrm{~s}$ (open circles) maximum load hold for (a) $80 \%$ and (b) $45 \%$ of the unloading curve from maximum load.

resulting in a lower stiffness. The reduced stiffness layer was also present when testing the dehydrated samples, implying that the softer surface may have resulted from mineral leaching in the wet condition. This could easily 


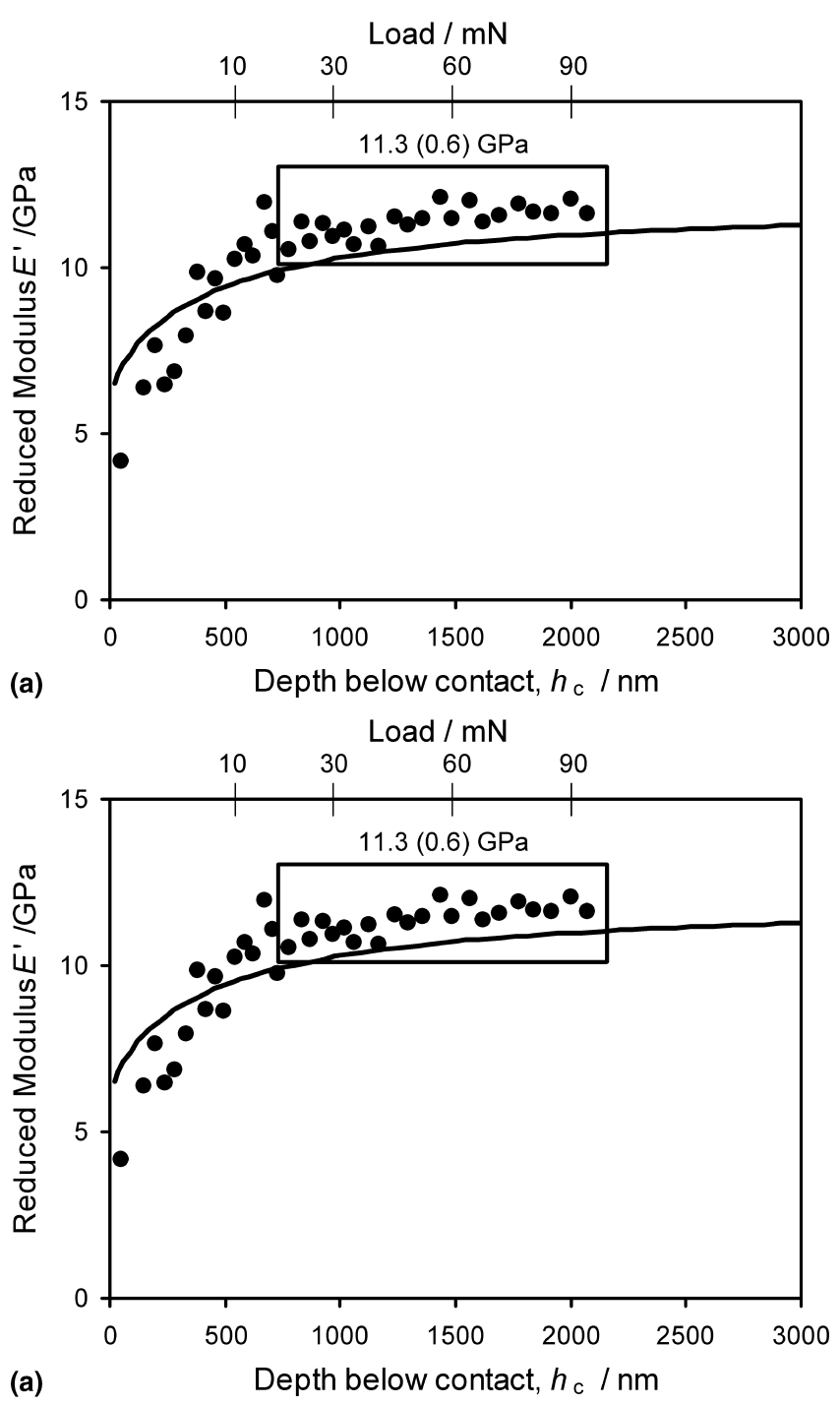

FIG. 6. $E^{\prime}$ versus $h_{\mathrm{c}}$ for the (a) $R=21-\mu \mathrm{m}$-radius indenter, wet (SCL) conditions and (b) $R=5$ - $\mu \mathrm{m}$-radius indenter, embedded condition, illustration that the low stiffness surface layer is eliminated in PMMA. Mean $E^{\prime}$ (SD), presented for each case is calculated from 25 data points shown in the boxed regions. The indentation loads are plotted along the top axis as a guide only because the loads are not linearly proportional to $h_{\mathrm{c}}$. Solid line in (a) is the finite element model of Fig. 7 plotted as $E^{\prime}$ versus $h_{\mathrm{c}}$ for comparison to show that the experimental data can be interpreted using a thin film model.

be confirmed in future studies by examining the indentation behavior of bone samples that were only stored in ethanol and never allowed to sit in a water-based medium. The composition of the SCL used in this examination may have contributed to the reduced modulus at the surface while an alternate solution might not, ${ }^{9}$ thus necessitating a careful examination of the effects of storage media on near-surface mechanical properties in future studies.

We may estimate the thickness of the reduced stiffness layer from the data in Fig. 6(a) using the surface layer analogy. Taking the "leveling out of the curve" to begin

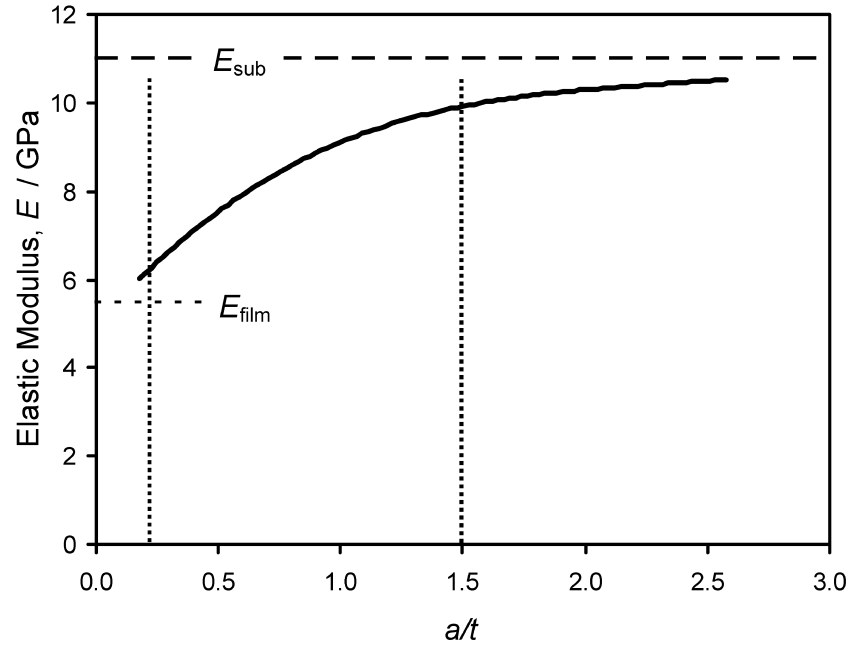

FIG. 7. Elastic modulus as a function of $a / t$ for a thin film on a substrate, from finite element modeling. (ABACUS, linear elastic, axisymmetric, rigid sphere of $R=20 \mu \mathrm{m}$ contacting layer of thickness $t=4 \mu \mathrm{m}$ and $E_{\text {film }}=5.5 \mathrm{GPa}$ on substrate with $E_{\text {sub }}=11 \mathrm{GPa}$, Poisson's ratio $=0.3$ for both layer and substrate.)

at $a / t \approx 1.5$ (Fig. 6), corresponding to $h_{\mathrm{c}} \approx 1000 \mathrm{~nm}$ [Fig. 6(a)], we calculate a value of $a=5.3 \mu \mathrm{m},{ }^{26}$ which implies the thickness of the surface layer to be of the order $3.5 \mu \mathrm{m}$. This suggests that the reduced stiffness layer is deeper than the surface roughness alone and may be evidence of leaching of mineral from the near surface region or, more likely, the movement of unbound water. The effect is greatly reduced for the embedded samples where an improved surface finish can be achieved and any demineralized surface layer is machined away, Fig. 6(b).

\section{B. Effective volume of elastic measurement}

We may estimate the volume of material that contributes to the elastic modulus measurement by, again, drawing on the thin film analogy. From Hertzian contact mechanics, the elastic stress field falls off as an inverse square law in the far field, and so theoretically extends to infinity-albeit at very small elastic strains. For indentation of a thin film on a substrate, the measured elastic response is always a composite of both the film and substrate modulus that varies as a function of $a / t$. There is therefore no depth at which the measured value can entirely be attributed to the film. ${ }^{32,33}$ However, using the results of the finite element model for a thin film on a substrate (Fig. 7), at a penetration of $a / t \approx 0.2$, the elastic response of the heterostructure approaches to within $10 \%$ of the film modulus. This implies that most of the volume of material contributing to modulus measurement lies within $5 a$ of the surface. The extent of the Hertzian stress field scales with both $a$ and the mean pressure acting over the contact area, $p_{\mathrm{m}}$. Tracing the contour of the principle stress for $0.005 p_{\mathrm{m}}$ (e.g., Ref. 34) and taking this as 
the boundary of the volume contributing to the measured elastic modulus, we may approximate the shape of this volume to a paraboloid of revolution with radius $3 a$ and depth $5 a$.

We compare the test volumes for the different indenters used in this study in Table II using typical data from individual indentations that gave modulus values very close to the mean for that data set. The elastic modulus measured for the whole data set for each indenter and each condition are summarized in Table III as the mean, standard deviation, and number of tests in each data set. It can be seen from Table II that test volumes for the Berkovich indenter at $5 \mathrm{mN}$ load and the $5 \mu \mathrm{m}$ radius spherical indenter at $15 \mathrm{mN}$ load are similar while those of the $21 \mu \mathrm{m}$ radius spherical indenter at $100 \mathrm{mN}$ load are an order of magnitude greater. The test volume for embedded material is about one-quarter of that for the wet material. Although the contact areas for the Berkovich and 5- $\mu \mathrm{m}$-radius spherical indenter are about $10 \mu \mathrm{m}^{2}$, in all cases the volume of material contributing to the modulus is greater than this and extends to a depth of between $10 \mu \mathrm{m}$ and $30 \mu \mathrm{m}$. The structural element of the bone that is sampled therefore includes several lamellae. There will be significant differences between the stiffness of adjacent lamellae due to any changes in the orientation of the collagen fibrils. As the volume increases, the effect of variation in the different directions in the individual lamellae, the differences in the degree of mineralization, and the presence of microstructural defects and canal spaces beneath the indentation site will be averaged over the larger volume. For the wet material, the standard deviations of the elastic modulus data tend to decrease as the test volume increases, which may in part be due to this averaging effect of the greater volume. Also for the wet material, as the volume increases the effect of the reduced stiffness layer decreases in the measured values. If the layer is of the order $3.5 \mu \mathrm{m}$ in depth, then its effect is largely eliminated for the $21 \mu \mathrm{m}$ radius indenter by taking data from contact depths of more than $1000 \mathrm{~nm}$. For the Berkovich and $5 \mu \mathrm{m}$ radius indenter, however, the elastic-modulus measurements would relate to $a / t<1$ and so are reduced by the effect of the surface layer. The effect of asperity contact would be expected to increase with contact area and hence $a$. For the embedded samples a much higher spatial resolution is achieved (factor of 4 ) compared to the wet
TABLE II. Typical values for the radius of contact circle, $a$, contact area, $A_{\mathrm{c}}$, mean pressure, $p_{\mathrm{m}}$, and an estimate of the test volume contributing to elastic modulus measurement, $V_{\mathrm{e}}$, for the three indenter geometries used in this study.

\begin{tabular}{cccc}
\hline \hline & $\begin{array}{c}\text { Berkovich } \\
(5 \mathrm{mN})\end{array}$ & $\begin{array}{c}R=5 \mu \mathrm{m} \\
(15 \mathrm{mN})\end{array}$ & $\begin{array}{c}R=21 \mu \mathrm{m} \\
(100 \mathrm{mN})\end{array}$ \\
\hline Wet (SCL) & & & \\
$a(\mu \mathrm{m})$ & 2.54 & 3.05 & 5.85 \\
$A_{\mathrm{c}}\left(\mu \mathrm{m}^{2}\right)$ & 20.3 & 29.2 & 108 \\
$p_{\mathrm{m}}(\mathrm{MPa})$ & 248 & 513 & 931 \\
$V_{\mathrm{e}}\left(\mu \mathrm{m}^{3}\right)$ & 1150 & 2000 & 14,100 \\
Embedded & & & \\
$a(\mu \mathrm{m})$ & 1.61 & 1.81 & 4.54 \\
$A_{\mathrm{c}}\left(\mu \mathrm{m}^{2}\right)$ & 8.14 & 10.3 & 64.8 \\
$p_{\mathrm{m}}(\mathrm{MPa})$ & 612 & 1460 & 1540 \\
$V_{\mathrm{e}}\left(\mu \mathrm{m}^{3}\right)$ & 296 & 419 & 6630 \\
\hline \hline
\end{tabular}

material while the effects of the surface layer are greatly reduced [Fig. 6(b)].

\section{Substitution of water with ethanol or PMMA}

The histograms in Fig. 8 show the distribution of elastic modulus values evaluated with the large radius $(R=$ $21 \mu \mathrm{m}$ ) indenter under the conditions of (a) wet, (b) dehydrated in $100 \%$ ethanol, and (c) embedded in PMMA. The distribution of values observed reflects the range of mineralization within the different packets of bone sampled, which includes both lamellar bone at different stages of the remodeling cycle and interstitial bone, together with the effects of orientation of the structure (Fig. 2). The distribution is typical for the normal range of mineralization in compact bone. ${ }^{3}$ The mean elastic modulus clearly increases significantly from wet conditions to $100 \%$ ethanol $(p<0.001$ : one-way analysis of variance, Bonferroni follow-on, $\alpha=0.05$ ) to embedded in PMMA $(p<0.001)$, Table III. However, the shape of the distribution changes little for each condition and is mainly indicative of the mineralization of the bone rather than the uncertainty of the test method. Replacing the water and embedding in resin appears therefore to offset the mean modulus values by a factor without changing the relative range of values. For the Berkovich indenter and the smaller radius $(R=5 \mu \mathrm{m})$ spherical indenter, a similar trend in increasing mean modulus is observed. In general, the standard deviations were always higher for the Berkovich indentations, possibly due to the fact that

TABLE III. Values (mean [SD], $n=$ ) of indentation modulus, $\mathrm{E}^{\prime}(\mathrm{GPa})$, from nanoindentation or storage modulus from DMA for each treatment.

\begin{tabular}{lcccc}
\hline \hline & Berkovich & $R=5 \mu \mathrm{m}=21 \mu \mathrm{m}$ & \multicolumn{1}{c}{ DMA } \\
\hline Wet (SCL) & $11.2(2.8), 308$ & $9.9(1.9), 117$ & $11.7(1.7), 326$ & $14.3(0.7), 8$ \\
$100 \%$ ethanol & $12.5(3.4), 345$ & $\mathrm{n} / \mathrm{a}$ & $15.0(2.2), 309$ & $17.3(1.4), 8$ \\
Embedded & $19.5(2.7), 349$ & $18.1(2.4), 548$ & $19.4(2.1), 283$ & \\
\hline \hline
\end{tabular}

Nanoindentation modulus values are presented from tests at $5 \mathrm{mN}$ (Berkovich), $15 \mathrm{mN}(R=5 \mu \mathrm{m})$, and $100 \mathrm{mN}(R=21 \mu \mathrm{m})$. DMA data are mean values for storage modulus, calculated from $0.6-10 \mathrm{~Hz}$ for each beam. 


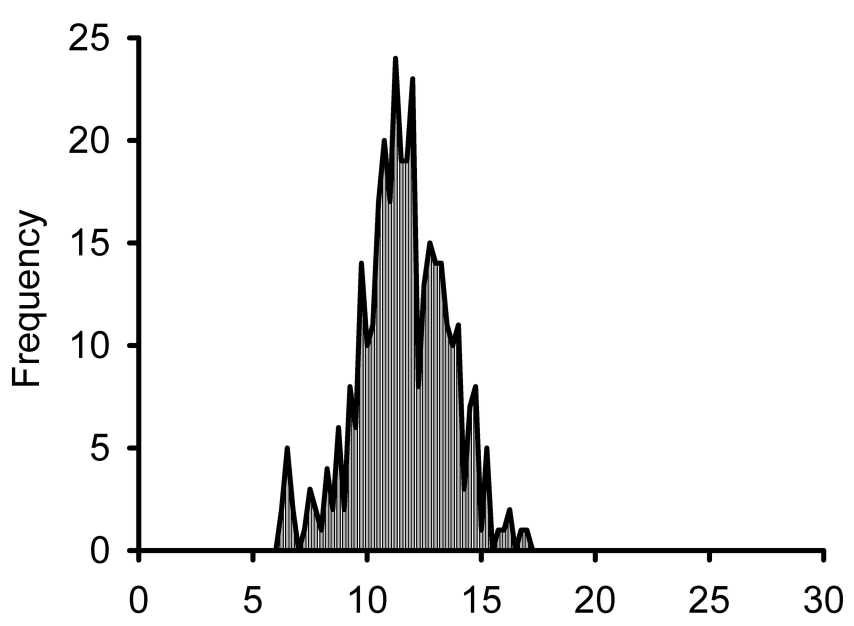

(a)

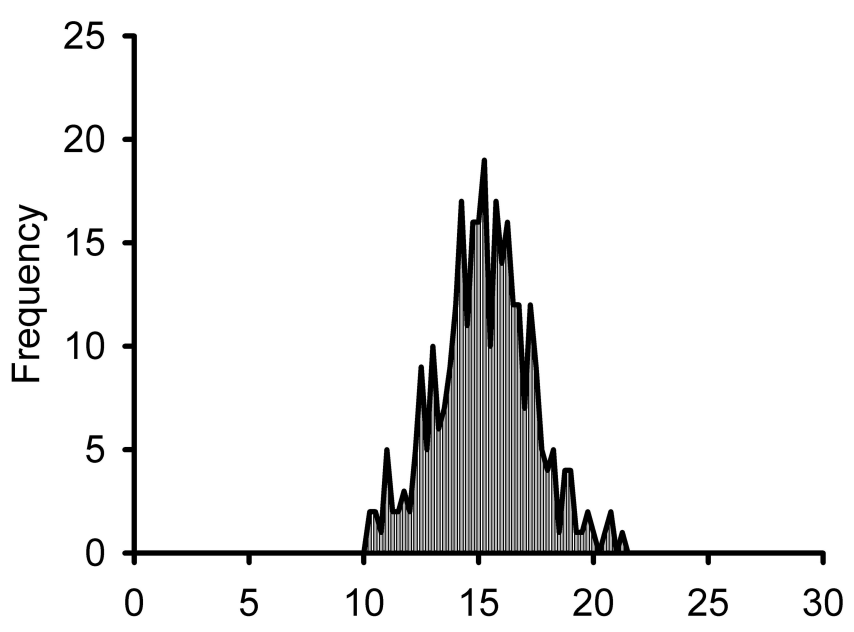

(b)

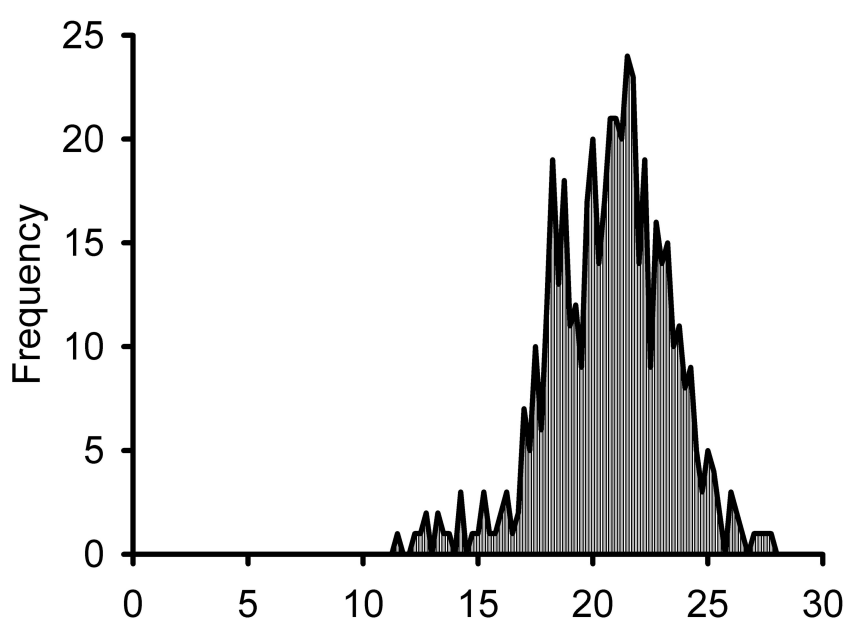

(c)

Elastic Modulus, E' / GPa

FIG. 8. Histograms of indentation modulus values using the $21-\mu \mathrm{m}-$ radius spherical indenter at a maximum load of $100 \mathrm{mN}$ of $100 \mathrm{mN}$ in (a) wet (SCL), (b) 100\% ethanol, and (c) embedded in PMMA. Pooled data for all eight beams. a single value is derived from each test whereas for the spherical indenters, the data are averaged over a range of contact depth for each indentation test (Fig. 6). The data for indentation of embedded beams is most consistent for the three different indenters used, in spite of the fact that they sample different volumes of the material. Measured values for the PMMA were also comparable for all three indenter tips $(4.8 \pm 0.2,5.0 \pm 0.1 \mathrm{GPa}$, and $4.9 \pm 0.2 \mathrm{GPa}$, for the Berkovich tip at $5 \mathrm{mN}, R=5 \mu \mathrm{m}$ at $15 \mathrm{mN}$ and $R=21 \mu \mathrm{m}$ at $100 \mathrm{mN}$ maximum load, respectively). The superior surface finish and stabilization of the embedded bone samples allows a much smaller volume to be sampled by testing at lower maximum force. Embedding also provides a continuum for load transfer over void space and microstructural defects, and may perform a function that is similar to that of confined fluids in pore space in vivo.

The DMA of the beams in three-point bending follows the same trend as the nanoindentation data with the wet sample displaying the lowest mean elastic modulus, beams in ethanol showing an increased modulus, and embedded beams showing the highest mean modulus values. The DMA determines the storage modulus from beam theory as an averaged, or Young's, modulus and so includes the effect of Poisson's ratio. ${ }^{28}$ The nanoindentation method determines a plane strain modulus and requires a value of Poisson's ratio to be used (determined independently) to obtain Young's modulus. Assuming a value of 0.3 for the Poisson's ratio of bone, we obtain values for Young's modulus from the $21 \mu \mathrm{m}$ radius spherical indenter of 10.7 GPa, 13.7 GPa, and 17.7 GPa for the wet, dehydrated, and embedded samples, respectively. Comparing these to the values from DMA testing in Table III, we note that the DMA records a value for the wet samples that is $34 \%$ greater than nanoindentation. The flexural loading in the DMA stresses the material in the plane of the beam while the indentation method loads the sample primarily in the transverse direction.

The equine McIII shaft bone was chosen for this study because the cortical bone is relatively uniform with a low porosity. In the radius, a similarly loaded bone in the equine forelimb, 25-35\% differences in elastic modulus have been observed between the longitudinal and transverse directions of the bone. ${ }^{14}$ This is attributed to the fact that the major structural subdivisions of the compact bone tissue, the osteons, are aligned to within a few degrees of the long axis of the bone. The difference in elastic modulus between the two test directions is extreme for these bones and reflected in the difference between indentation (primarily transverse) and longitudinally loaded (DMA) data. The stress field beneath the indenter is almost radial in nature and so is relatively insensitive to elastic anisotropy in single crystals, such as silicon. However, for such complex composite materials as bone, the changes in measured elastic 
properties with orientation must reflect the organization of the microstructure.

The increase in elastic modulus for the bone samples where the unbound water in the tissue has been replaced with ethanol is greater than might be expected from the replacement of one liquid by another, as though the unbound water also plays a role in the structure. Removing the bound water by, for instance, vacuum drying results in greater tissue shrinkage and cracking, and may result in a $10-15 \%$ increase in indentation modulus. ${ }^{15}$ Water may act as a plasticizer to the collagen fibrils and fill fine pore space between fibrils and perhaps between mineral crystallites. Water molecules may contribute to the stability of the collagen, and dehydration may cause a conformational change in the collagen that results in increased stiffness. ${ }^{35,36}$ However, the ethanol does not appear to act in the same manner and may constrict movement of the collagen allowing greater load transfer within the material.

The DMA modulus for beams in $100 \%$ ethanol is $27 \%$ greater than that of nanoindentation, which is less than the difference for wet beams, as though the nanoindentation measurement is becoming less orientation sensitive. The trend continues with embedding in PMMA where the DMA modulus is only $20 \%$ greater than the nanoindentation value. Now the liquid space occupied by water is entirely replaced by solid PMMA resin, further constricting the movement of the collagen fibrils and increasing the connectivity within the material.

Replacing the ethanol with PMMA resin further increases the stiffness of the tissue, of the order $35 \%$ over wet tissue. This represents a far greater increase than might be expected from a rule of mixtures, as the volume of large spaces within the bone (canal space) occupies some $5-10 \%$ of the volume. However, in nanoindentation we do not test close to canals. Within the "solid" bone tissue, osteocytic lacunae and canaliculi occupy $1-2 \%$ of the space. Canaliculi have diameters of the order $0.5 \mu \mathrm{m}$, extend from and join adjacent osteocyte lacunae and connect them with internal (e.g., canal) surfaces. Lacunae have typical dimensions of $5 \times 10 \times$ $25 \mu \mathrm{m}$. This finer, canalicular and lacunar pore space is detected in the nanoindentation test, and when filled with PMMA resin increases the stiffness of the tissue significantly. The role of water in ultrastructural, nanometric fine pore space is not clear, but its replacement by ethanol and PMMA shows that it plays an important role in the stiffness of the bone structure.

\section{CONCLUSIONS}

The elastic properties of bone, including wet bone, can be measured by nanoindentation using appropriate methodologies. Similar values were obtained using Berkovich and spherical indenter geometries and different loading sequences. For the Berkovich indenter, an adequate maximum load hold period was essential to achieving reliable data. Fitting the unload curve to determine the contact depth was improved by fitting to only the upper $45 \%$ of the unload curve. The residual term to the fit $\left(r^{2}\right)$ is itself not a good indicator of a suitable fit to the initial unloading curve.

Multiple partial unloading using a spherical indenter revealed a reduced indentation modulus of a near surface layer for wet and ethanol bone samples. The layer was estimated to be of the order several micrometers in depth and may be due to surface roughness, local demineralization, or the mobility of water near the free surface of the tissue. For small indenters and relatively low loads, this layer reduces the measured modulus value. Careful selection of storage media and examination of the effects of the media on the tissue is therefore critical. Indenting with a large-radius indenter to higher loads increases the volume of material contributing to the elastic modulus measurement and reduces surface effects on the measured modulus value. Embedding tissue in PMMA produced consistent modulus values regardless of the indenter geometry used and allows higher spatial resolution information to be obtained.

Replacing the unbound water with ethanol results in a 15-20\% increase in measured elastic modulus. Embedding in PMMA increased the modulus more strongly than would be expected from a consideration of the volume fraction of resin. Similar trends were observed in the DMA testing. The role of water in fine pore space is not clear but its replacement by ethanol and PMMA shows that the mechanical behavior of bone is strongly influenced by it.

\section{ACKNOWLEDGMENTS}

We thank R. Radcliffe and M. Arora for technical assistance and C. Chima-Okereke for generating the finite element model. We are very grateful to A.E. Goodship for provision of the samples and to M.V. Swain for assistance and useful discussions in the initial stages of this work.

\section{REFERENCES}

1. R.B. Martin and D.L. Boardman, J. Biomech. 26, 1047 (1993).

2. R.B. Martin and J. Ishida, J. Biomech, 22, 419 (1989).

3. V.L. Ferguson, A.J. Bushby, and A. Boyde, J. Anat. 203, 191 (2003).

4. P. Lucksanasombool, W.A.J. Higgs, R.J.E.D. Higgs, and M.V. Swain, Biomaterials 22, 3127 (2001).

5. J.J. Broz, S.J. Simske, A.R. Greenberg, and M.W. Luttges. J. Biomech. Eng. 115, 447 (1993).

6. J.D. Currey, J. Biomech. 21, 439 (1988). 
7. J. Menčík and M.V. Swain, J. Mater. Res. 10, 1491 (1995).

8. M.B. Gustafson, R.B. Martin, V. Gibson, D.H. Storms, S.M. Stover, J. Gibeling, and L. Griffin, Calcium buffering is required to maintain bone stiffness in saline solution. J. Biomech. 29, 1191 (1996).

9. S. Habelitz, G.W. Marshall, Jr., M. Balooch, and S.J. Marshall, J. Biomech. 35, 995 (2002).

10. G.W. Marshall, Jr., I.C. Wu-Magidi, L.G. Watanabe, N. Inai, M. Balooch, J.H. Kinney, and S.J. Marshall, J. Biomed. Mater. Res. 42, 500 (1998).

11. M. Balooch, I.C. Wu-Magidi, A. Balazs, A.S. Lundkvist, S.J. Marshall, G.W. Marshall, W.J. Siekhaus, and J.H. Kinney, J. Biomed. Mater. Res. 40, 539 (1998).

12. G.P. Evans, J.C. Behiri, J.D. Currey, and W. Bonfield, J. Mater. Sci. Mater. Med. 1, 38 (1990).

13. S.J. Simske, J.J. Broz, and M.W. Luttges, Effect of suspension on mouse bone microhardness. J. Mater. Sci. Mater. Med. 6, 486 (1995).

14. J-Y. Rho, J.D. Currey, P. Zioupos, and G.M. Pharr, J. Exp. Biol. 204, 1775 (2001).

15. J-Y. Rho and G.M. Pharr, J. Mater. Sci. Mater. Med. 10, 485 (1999).

16. S. Hengsberger, A. Kulik, and P.H. Zysset, Bone 30, 178 (2002).

17. C.H. Turner, J. Rho, Y. Takano, T.Y. Tsui, and G.M. Pharr, J. Biomech. 32, 437 (1999).

18. F.G. Evans and M. Lebow, J. Appl. Physiol. 3, 563 (1951).

19. P.G. Howell and A. Boyde, Scanning 21, 361 (1999).

20. P.K. Zysset, X.E. Guo, C.E. Hoffler, K.E. Moore, and S.A. Goldstein, J. Biomech. 32, 1005 (1999).

21. J-Y. Rho, P. Zioupos, J.D. Currey, and G.M. Pharr, Bone 25, 295 (1999).

22. J.H. Kinney, M. Balooch, S.J. Marshall, G.W. Marshall, Jr., and
T.P. Weihs, Hardness and Young's modulus of peritubular and intertubular dentine Archs. Oral Biol. 41, 9 (1996).

23. K. Herrmann, N.M. Jennett, W. Wegener, J. Meneve, K. Hasche, and R. Seeman, Thin Solid Films 377-378, 394 (2000).

24. W. Oliver and G.M. Pharr, J. Mater. Res. 7, 1564 (1992).

25. J.S. Field and M.V. Swain, J. Mater. Res. 8, 297 (1993).

26. A.J. Bushby, Non-Destruct. Test. Eval. 17, 213 (2001).

27. A.J. Bushby and N.M. Jennett, in Fundamentals of Nanoindentation and Nanotrilology II, edited by S.P. Baker, R.F. Cook, S.G. Corcoran, and N.R. Moody (Mater. Res. Soc. Symp. Proc. 649, Warrendale, PA, 2001), Q7.17.

28. K.P. Menard, Dynamic Mechanical Analysis: A Practical Introduction (CRC Press, Boca Raton, London, 1999), pp. 208.

29. M. Oyen-Tiesma, Y.A. Toivola, and R.F. Cook, in Fundamentals of Nanoindentation and Nanotribology III, edited by S.P. Baker, R.F. Cook, S.G. Corcoran, and N.R. Moody (Mater. Res. Soc. Symp. Proc. 649, Warrendale, PA, 2001), Q15.1.

30. T. Chudoba and F. Richter, Surf. Coat. Technol. 148, 191 (2001).

31. B.J. Briscoe, L. Fiori, and E. Pelillo, J. Phys. D: Appl. Phys. 31, 2395 (1998).

32. J. Mencik, D. Munz, E. Quandt, E.R. Weppelman, and M.V. Swain, J. Mater. Res. 12, 2475 (1997).

33. N.M. Jennett and A.J. Bushby, in Thin Films: Stresses and Mechanical Properties IX, edited by C.S. Ozkan, L.B. Freund, R.C. Cammarata, and H. Gao (Mater. Res. Soc. Symp. Proc. 695, Warrendale, PA, 2002), p. 73.

34. A.C. Fischer-Cripps, Introduction to Contact Mechanics (Springer-Verlag, New York, 2000).

35. G. Melacini, A.M.J.J. Bonvin, M. Goodman, R. Boelens, and R. Kaptein, J. Mol. Biol. 300, 1041 (2000).

36. H. Saito and M. Yokoi, J. Biochem. (Tokyo) 111, 376 (1992). 